account as well as by reducing myocardial oxygen consumption. This may explain the effectiveness of the drug. Perhexiline does not block beta-receptors, and though it has been shown expetimentally to have a quinidine-like action in rat, rabbit, and dog hearts it is difficult to reconcile this action with reduction of exercise tachycardia alone.

The results in this trial are similar to those reported previously on perhexiline in the United States (Hirshleifer, 1969; Winsor, 1970; Lyon et al., 1971). All trials indicate that perhexiline is effective in angina pectoris-indeed patients in this study had relief from angina when other drugs, including beta-blockers, had failed.

The commonest side effect in all trials has been vertigo or dizziness, with a lesser incidence of nausea and vomiting, weakness, and lethargy. Side effects usually appear within the first week of starting the drug but fortunately many are transient and subside on continued medication. The incidence of side effects correlates with body weight of the patients; probably many side effects may be avoided in future by reducing dosage.

Unlike most trials on beta-blocking agents, this study was undertaken without a "run-in" period in which to determine the maximal effective dose. This has the advantage of removing built-in bias towards the drug that such a run-in will produce, but it also means that the optimal dosage is not necessarily achieved.

Though the code was never broken until the end of the study, in some instances the relief of angina was so dramatic and in others the side effects were so definite that both patient and doctor strongly suspected that they could distinguish perhexiline from placebo. The former, at least, is an unavoidable aspect of any study in which a drug is assessed for its efficacy in preventing pain and is found to be successful.

Laboratory studies were made on all patients in this trial and in other trials previously reported. No abnormalities were found in tests of haematological or renal function nor in serum electrolytes, cholesterol, or blood glucose. In the United States no consistent trends of abnormalities have been reported in liver function tests, but in three of the four centres here some rises in SGOT levels were seen. Unlike the subjective side effects, these biochemical abnormalities did not appear soon-in most patients only after three to four weeks' therapy. All these patients remained well and asymptomatic.

We consider that perhexiline is a valuable drug for treating angina and is particularly useful in: (1) patients with severe angina and especially those who have failed to respond to other antianginal drugs, notably beta-blockers; many patients in this trial had been previously treated unsuccessfully with betablockers and long-acting nitrates before successful therapy with perhexiline; (2) patients in whom the resting heart rate is slow enough for beta-blockade to be considered dangerous; and (3) patients in whom bronchospasm is a problem; Feinsilver et al. (1970) showed that perhexiline caused bronchodilatation in asthmatic patients. Though practolol has little bronchospastic action, no antianginal drug other than perhexiline has a bronchodilator effect.

Perhexiline may also be safer to use than beta-blocking agents in patients with congestive heart failure.

We are grateful to Dr. J. P. Birkett, of Richardson-Merrell Limited, for advice and for the supplies of perhexiline maleate and placebo tablets used in the study.

Requests for reprints should be sent to Dr. C. J. Burns-Cox, Department of Medicine, Frenchay Hospital, Bristol BS16 1LE.

\section{References}

Cho, Y. W., Belej, M., and Aviado, D. M. (1970). Chest, 58, 577.

Feinsilver, O., Cho, Y. W., and Aviado, D. M. (1970). Chest, 58, 558

George, C. G., Nagle, R. E., and Pentecost, B. L. (1970). British Medical fournal, 2, 402 .

Gillam, P. M. S., and Prichard, B. N. C. (1965). British Medical Fournal, 2 , 337.

Grupp, I. L., Bunde, C. A., and Grupp, G. (1970). Fournal of Clinical Pharmacology and fournal of New Drugs, 10, 312

Hirshleifer, I. (1969). Current Therapeutic Research, 11, 99.

Hudak, W. J., Lewis, R. E., and Kuhn, W. L. (1970). Fournal of Pharmacology and Experimental Therapeutics, 137, 371 .

Keelan, P. (1965). British Medical fournal, 1, 897.

Lyon, L. J., Nevins, M. A., Fisch, S., and Henry, S. (1971). Lancet, 1, 1272. Martins de Oliveira, J., and de Almeida Amado, N. J. (1970). Hospital (Rio de faneiro), 77, 1511.

Wilson, D. F., Watson, O. F., Peel, J. S., and Turner, A. S. (1969). British Medical fournal, 2, 155.

Winsor, T. (1970). Clinical Pharmacology and Therapeutics, 11, 85.

\title{
Effect of Resection of Lung Tumours on the Steroid Abnormalities in Patients with Lung Cancer
}

\author{
L. G. S. RAO
}

British Medical fournal, 1971, 4, 588-590

\section{Summary}

The urinary excretion of androsterone, aetiocholanolone, total 17-oxosteroids, and 17-hydroxycorticosteroids (17OHCS) was measured in 40 patients with lung cancer three days before resection and again 10-15 days after resection of their lung tumours. There was a significant postoperative increase in the excretion of 17-OHCS but a significant decrease in the excretion of androsterone and aetiocholanolone, resulting in an increase of the preoperative abnormalities in steroid excretion in these patients. Since there was no change in steroid excretion

Psychosomatic Research Unit, Department of Psychological Medicine, Southern General Hospital, Glasgow S.W.1

L. G. S. RAO, M.SC., PH.D., Research Fellow towards normal after resection of the lung tumours, it seems that the steroid abnormalities found in lung cancer are not the effect of the presence of the lung tumours. As the excretions of 17-OHCS and 11-deoxy17-oxosteroids change in opposite directions after resection, it is suggested that a dissociation of factors that control the excretion of these two groups of steroids takes place as a response to surgical stress in patients with lung cancer.

\section{Introduction}

Previous work from this laboratory (Rao, 1970) has shown that most patients with lung cancer show several abnormalities in the excretion of 17-oxosteroids (17-OS) and 17-hydroxycorticosteroids (17-OHCS). These abnormalities have been combined into discriminant function which seems to be of diagnostic and prognostic value (Rao, 1970; Rao and Hewit, 1970). The 
important question that arises out of this is whether the steroid abnormalities are the cause or effect of cancer. It was therefore decided to investigate if any qualitative or quantitative change took place in the abnormalities in steroid excretion in lung cancer after the removal of the lung tumours by surgical resection.

\section{Patients and Methods}

Forty men aged 34-66 (mean 55.6) years admitted to chest departments in hospitals in and around Glasgow for surgical treatment of their lung cancers were investigated. All patients had had successful resection of their lung tumours either by lobectomy or pneumonectomy and had no evidence of residual primary tumour or of metastases at the time of resection. Two of the 40 patients had adenocarcinoma, three had oat-cell carcinoma, and the rest had epidermoid carcinoma of varying degrees of differentiation. Two consecutive early morning urine specimens were collected about three days before and again at least 10 days after surgery. The steroid content (the mean of the duplicate determinations of the two consecutive specimens) has been expressed as milligrammes of steroid per gramme of creatinine per litre. The laboratory methods have been described (Rao, 1970).

\section{Results}

The excretion of androsterone, aetiocholanolone, 17-OS, and $17-O H C S$ before and after resection of the lung tumours is given in the Table and in Figs. 1 and 2. The preoperative 17-OHCS excretion was in normal range $(4.9-15.6 \mathrm{mg} / \mathrm{g}$ creatinine/1.) and therefore this group does not appear to include any patients with ectopic ACTH production though the mean level of $17-\mathrm{OHCS}$ excretion was higher than in normal men (Rao, 1970).

Steroid Excretion before and after Resection of Lung Tumour in Patients with Lung Cancer (mg/g creatinine/l.)

\begin{tabular}{|c|c|c|c|c|c|}
\hline & $\mathrm{N}$ & A & $\mathrm{E}$ & $17-$ OS & 17-OHCS \\
\hline $\begin{array}{l}\text { Before resection } \\
\text { After resection }\end{array}$ & $\begin{array}{l}40 \\
32\end{array}$ & $\begin{array}{l}1.38 \div 0.44 \\
1.01 \div 0.52^{*}\end{array}$ & $\begin{array}{l}2.08 \pm 1.06 \\
1.48 \pm 0.83^{*}\end{array}$ & $\begin{array}{l}6.12 \pm 1.88 \\
6.01 \pm 1.98\end{array}$ & $\begin{array}{l}8.36 \pm 2.66 \\
11.48 \pm 3.85 *\end{array}$ \\
\hline
\end{tabular}

* Significantly different from preoperative values $(P<0.01)$.

$\mathrm{N}=$ Number of patients. $\mathrm{A}=$ Androsterone. $\mathrm{E}=$ Aetiocholanolone.

The steroid values are given as the mean of duplicate determinations of two consecutive early morning urine specimens. The preoperative specimens were collected about three days
after resection.

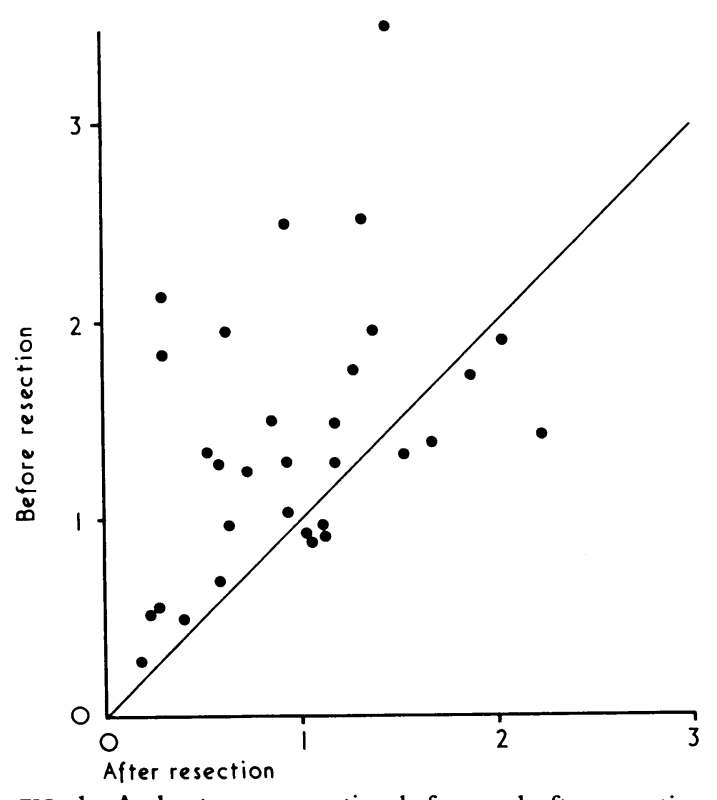

FIG. 1-Androsterone excretion before and after resection of lung tumours $(\mathrm{mg} / \mathrm{g}$ creatinine/l.)

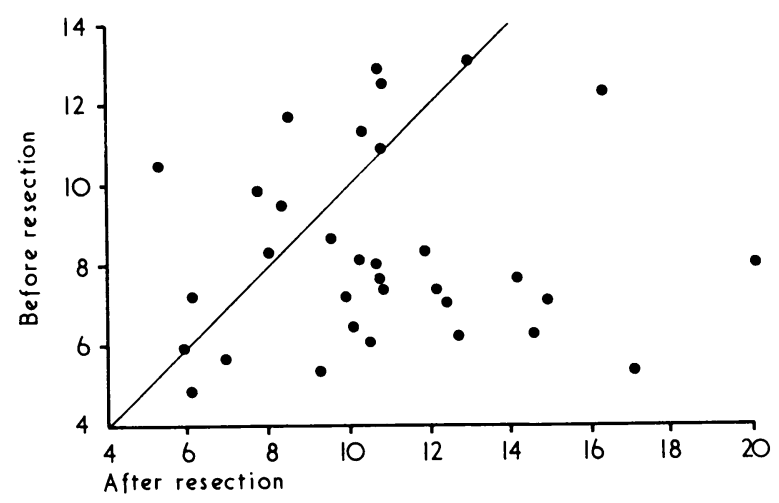

FIG. 2-17-OHCS before and after resection of lung tumours (mg/g creatinine/l.)

A significant decrease in the excretion of androsterone and aetiocholanolone was found after resection whereas there was a significant increase in the excretion of 17-OHCS. There was no significant change in the excretion of the total 17-OS. In eight patients the values for the excretion of androsterone and aetiocholanolone could not be obtained because these two compounds remained unresolved on the gas-chromatograph. The chemical nature of the substance found in this unresolved peak is not known and is under study.

\section{Discussion}

It should be important to investigate whether the steroid abnormalities found in lung cancer are the effects of the tumour or not, because these steroid abnormalities seem to be of diagnostic and prognostic value in patients with this disease (Rao, 1970; Rao and Hewit, 1970). This question of cause or effect is particularly relevant in lung cancer as it is known that some lung tumours produce polypeptides with ACTH-like properties (British Medical Fournal, 1968). Surgical removal of the tumour results in an immediate return to normal steroid excretion in the case of ectopic ACTH-producing tumours (Jones et al., 1969). It is also known that some tumours can metabolize steroid hormones (Adams and Wong, 1968). In the present study, however, it is shown that the steroid abnormalities do not disappear after resection.

Androsterone, which was excreted in significantly reduced amounts before resection, did not show an increase but a further decrease after surgery. Aetiocholanolone, which was excreted in normal amounts before resection, showed a decrease after resection. The androsterone/aetiocholanolone ratio, which was abnormally low before resection, continued to be the same after resection. The 17-OHCS, which were excreted in significantly larger amounts than in normal men before resection, showed a further increase even 10 days after surgery. Thus the abnormalities in steroid excretion increase in magnitude after resection. The changes in steroid excretion after mastectomy in patients with breast cancer (Bulbrook and Hayward, 1967) are similar to those in lung cancer after pneumonectomy or lobectomy in that there is an increased excretion of 17-OHCS while there is a decreased excretion of 11-deoxy-17-oxosteroids compared with their preoperative values. An increased level of 17-OHCS excretion even at two weeks after surgery indicates the persistence of surgical stress in these patients. Thus steroid excretion after removal of tumours will include the response to the physical and emotional stress after surgery.

Previous work on steroid excretion after surgical stress has shown that there is an increase in the excretion of both the $17-O S$ and the 17-OHCS in the first three days after surgery (Birke et al., 1955), and that excretion of all the steroids returns to normal in about 8 to 10 days. Steroid estimations after the stress of a myocardial infarction (Rao, unpublished) have also 
shown an increase in the excretion of the 17-OHCS as well as of the 11-deoxy-17-oxosteroids in the first three days and a return to normal in about a week. A decrease in androsterone and aetiocholanolone excretion while there is an increase in 17-OHCS excretion after resection in lung cancer seems to be an unusual response to surgical stress and indicates a separation of the factors controlling the excretion and possibly the secretion of the precursors of the 17-OHCS and the 17-OS. This dissociation of the factors that control the excretion of the 17-OS and the 17-OHCS as a response to surgical stress may persist for several months both in breast cancer (Bulbrook and Hayward, 1967) and in lung cancer (Rao, unpublished), and may be a characteristic of neoplastic disease in general.

I thank Miss Margaret L. Hewit, who carried out many of these steroid determinations with the help of Mr. G. Lynam and Mr. A Clarke; Dr. R. J. Cuthbert, Dr. J. Cuthbert, Dr. J. T. Boyd, Mr. J. Hutcheson, Mr. M. A. Turner, Mr. R. A. McCluskie, and Mr.
R. S. Barclay for the facilities to investigate patients under their care; the nursing staff for collecting specimens; and Professor T. Ferguson Rodger for his encouragement and interest. The Medical Research Council and the Tobacco Research Council provided financial assistance.

\section{References}

Adams, J. B., and Wong, M. S. (1968). Lancet, 2, 1163.

Birke, G., Franksson, C., and Plantin, L. O. (1955). Acta Endocrinologica (Kobenhavn), 18, 201.

British Medical fournal, 1968, 4, 5

Bulbrook, R. D., and Hayward, J. L. (1967). Current Concepts in Breast Cancer, ed. A. Segaloff, K. K. Mayer, and S. Debakey, p. 126. Baltimore, Williams and Wilkins.

Jones, J. E., Shane, S. R., Gilbert, E., and Flink, E. B. (1969). Fournal of Clinical Endocrinology, 29, 1.

Rao, L. G. S. (1970). Lancet, 2, 441.

Rao, L. G. S., and Hewit, M. (1970). Lancet, 2, 1063.

\title{
Amenorrhoea in Anorexia Nervosa: Assessment and Treatment with Clomiphene Citrate
}

\author{
J. C. MARSHALL, T. RUSSELL FRASER
}

British Medical fournal, 1971, 4, 590-592

\section{Summary}

Seven patients with anorexia nervosa were studied, three during the acute stages of the illness, and four in whom weight gain had been achieved, but who suffered from persistent amenorrhoea of 18 to 79 months' duration.

In the acute stage all patients had low serum luteinizing hormone (LH) levels which were unresponsive to clomiphene citrate. In those who had regained weight the mean basal LH levels were normal, and they responded to clomiphene with an initial doubling of serum LH during administration of the drug, followed by a second peak of serum LH four to seven days after the drug was stopped. Menstruation occurred in these patients 13 to 19 days after the clomiphene was discontinued, and in two patients regular spontaneous menstruation was initiated.

The low LH levels unresponsive to clomiphene in the acute stage provide evidence for a hypothalamic abnormality in anorexia nervosa. After regain of body weight the drug seems to be effective in treating the amenorrhoea which may be persistent.

\section{Introduction}

Amenorrhoea is a constant feature of anorexia nervosa occurring in girls after puberty. It usually begins early in the disease, after some weight loss has occurred (Russell and Beardwood, 1968), though it may antedate weight loss in some patients (Kay and Leigh, 1954). Commonly menses return with the regain of normal weight but may be delayed for months or years after weight gain has been achieved (Crisp and Stonehill, 1971).

\footnotetext{
Endocrine Unit, Department of Medicine, Royal Postgraduate Medical School, London W12 0HS

J. C. MARSHALL, B.SC., M.R.C.P., M.R.C. Clinical Research Fellow T. RUSSELL FRASER, M.D., F.R.C.P., Professor of Clinical Endocrinology
}

Most workers agree that urinary gonadotrophin levels are low during the illness (Bell, Harkness, Loraine, and Russell, 1966; Rakoff, 1968; Russell, 1970) and that this is the explanation of the amenorrhoea, though the mechanism of the reduced gonadotrophin secretion remains obscure. Studies of urinary gonadotrophin excretion during refeeding have shown that some gonadotrophin secretion returns with regain of weight. However, this is not proportional to weight gained and is incomplete, normal cyclical changes not being seen (Russell and Beardwood, 1968).

Clomiphene citrate has been shown to stimulate pituitary gonadotrophin secretion (Bardin, Ross, and Lipsett, 1967; Jacobson, Marshall, Ross, and Cargille, 1968; Marshall, Anderson, Burke, Galvao-Teles, and Fraser, 1970), but few data are available on its effect in anorexia nervosa or of its use as a therapeutic agent to stimulate the return of normal menses in this condition.

\section{Patients and Methods}

The diagnosis of anorexia nervosa was made using the criteria described by Russell (1970). Clinical details of the patients studied are given in the Table. Matched mean population weights were obtained from tables (Kemsley, 1952).

Serum luteinizing hormone $(\mathrm{LH})$ was measured with a double-antibody immunoassay. Medical Research Council Human Pituitary Research Standard "A" (ICSH/LH) 63/15 was used as the standard preparation. An ampoule of this material was defined as containing 10 "ampoule" units (hereafter termed units). In this assay 1 unit M.R.C. Standard "A" was equivalent to 8.4 international units of Second International Reference Preparation Human Menopausal Gonadotrophin. The normal range for the follicular phase of a menstrual cycle is $1.8-4.5 \mathrm{mU} / \mathrm{ml}$ (mean $2.7 \pm 0.49$ S.D.). Samples for $\mathrm{LH}$ estimation were taken before and at the end of clomiphene administration and when possible during the nine days after the course of clomiphene.

Clomiphene citrate (Clomid) was given in a dosage of $2 \mathrm{mg}$ / $\mathrm{kg} /$ day (50-75 mg/day) to patients in the acute stages of the illness, and in increasing doses (50-150 mg/day) to the anorexic 